\title{
The effects of a home-based physical activity intervention on cardiorespiratory fitness in breast cancer survivors; a randomised controlled trial
}

\section{Introduction}

Globally, breast cancer is the leading cause of cancer death and the most frequently diagnosed cancer among females (Ferlay et al., 2014). From 2008 to 2012, the number of women living with a diagnosis of breast cancer across the world increased from 5.2 to 6.2 million (Bray, Ren, Masuyer, \& Ferlay, 2012; Ferlay et al., 2014). Due to an increase in the number of women surviving breast cancer, owing largely to early detection and improved treatment strategies, we are now beginning to see the long-term consequences of a cancer diagnosis and treatment. One such long-term effect appears to be an excess of cardiovascular mortality in breast cancer survivors (Eloranta et al., 2012), particularly in those over the age of 65 (Patnaik, Byers, DiGuiseppi, Dabelea, \& Denberg, 2011). The precise reason for this increased risk of cardiovascular disease (CVD) is unknown. However, it is possible that prolonged exposure to aggressive adjuvant therapies, such as surgery, radiation therapy, and chemotherapy, can cause injury to components of the cardiovascular system. These cardi-

40 ovascular insults coupled with unfavourable lifestyle changes, such as weight gain and reduced physical activity (PA), can lead to an increased susceptibility to further cardiovascular damage and risk of premature CVD mortality (Hoff et al., 1979; Jones, Haykowsky, Swartz, Douglas, \& Mackey, 2007; Shan, Lincoff, \& Young, 1996). This phenomenon has been termed the "multiplehit" hypothesis (Jones et al., 2007).

A combination of disease pathology, treatment regimens, weight gain, and low PA can compromise cardiorespiratory fitness of breast cancer survivors (Jones et al., 2007). 50 Cardiorespiratory fitness, as measured by maximal oxygen uptake ( $\mathrm{VO}_{2}$ max), reflects the highest rate at which oxygen is transported and utilised by the body during maximal exercise (Bassett \& Howley, 2000). Breast cancer survivors have been reported as having $\dot{V O}_{2}$ max values $22-25 \%$ lower compared to their age matched healthy, sedentary non-cancer peers (Jones et al., 2012; Peel, Thomas, Dittus, Jones, \& Lakoski, 2014). In a recent review it was reported that post-adjuvant therapy breast cancer patients had a weighted mean $\dot{V}_{2}$ max of $22 \mathrm{ml} \cdot \mathrm{kg}^{-1} \cdot \mathrm{min}^{-1}$, a value $10 \%$ lower than that observed in pre-adjuvant therapy patients (Peel et al., 2014). Worringly, low cardiorespiratory fitness has been found to inversely associate with breast cancer-related deaths, cardiovascular and all-cause mortality (Blair, 1996; Peel et al., 2009). Peel and colleagues (2009) found that low cardiorespiratory fitness of below eight maximal metabolic equivalents (MET) (approximates a $\dot{V} \mathrm{O}_{2} \max$ of $28 \mathrm{ml} \cdot \mathrm{kg}^{-1} \cdot \mathrm{min}^{-1}$ ) was associated with a nearly three-fold increase in breast cancer deaths compared to those who reached 10 MET $\left(\sim 35 \mathrm{ml} \cdot \mathrm{kg}^{-1} \cdot \mathrm{min}^{-1}\right)$ or greater.

Encouragingly, increased PA associates with reduced CVD mortality in adults (Sattelmair et al., 2011), and improved CVD risk profile (Knobf \& Coviello, 2012; Thompson, Visich, Singleton, \& Saltarelli, 2003), fewer recurrences, and lower breast cancer-related mortality in women with breast cancer (Ibrahim \& Al-Homaidh, 2011; Lahart, Metsios, Nevill, \& Carmichael, 2015). Previous meta-analyses have found significant improvements in the cardiorespiratory fitness of breast cancer populations (during and after adjuvant therapy) participating in PA interventions within randomised controlled trials (Fong et al., 2012; Furmaniak, Menig, \&

CONTACT lan M. Lahart I.Lahart@wlv.ac.uk

๑ 2017 Informa UK Limited, trading as Taylor \& Francis Group 
80 Markes, 2016; Speck, Courneya, Mâsse, Duval, \& Schmitz, 2010). However, PA interventions involving breast cancer populations typically involve supervised, facility-based exercise programmes, which can be costly to run, time-consuming, and require access to specialist facilities. Therefore, given that health care resources are finite, more pragmatic interventions that can overcome some of the barriers stated above and improve the health of patients are more desirable to those making clinical, managerial and policy decisions.

Home-based PA interventions can potentially mitigate

90 many of the barriers to PA, such as transportation and scheduling difficulties, cost, and need for facilities (Pinto, Frierson, Rabin, Trunzo, \& Marcus, 2005). However, there are a limited number of randomised controlled trials that have investigated the effects of home-based PA interventions on cardiorespiratory fitness in breast cancer survivors (Fillion et al., 2008; Irwin et al., 2014; Pinto et al., 2005; Rogers et al., 2009). Only one of these previous studies (Irwin et al., 2014) assessed cardiorespiratory fitness using the gold standard method (i.e., $\dot{V}_{2}$ max measured via indirect calorimetry). The other previous studies used walking tests to assess cardiorespiratory fitness. Walking test outcome is dependent on a combination of movement efficiency, motor skills, and cardiorespiratory fitness, and therefore, a change in walking distance may not be fully representative of a change in $\dot{V} \mathrm{O}_{2} \max$ (Ekelund, 2008). Additionally, all previous home-based PA interventions that employed walk tests (Fillion et al., 2008; Pinto et al., 2005; Rogers et al., 2009) used change in single walk distance to represent changes in cardiorespiratory fitness, which has been found

110 to vary up to $33 \%$ more than a change in best-of-two walk distance (Chandra et al., 2012). Accordingly, a more precise measure of $\dot{V} \mathrm{O}_{2}$ max may be needed to elucidate actual changes in $\dot{V O}_{2}$ max. Therefore, the aim of this current study was to investigate the effects of a home-based PA intervention on the cardiorespiratory fitness $\left(\dot{V}_{2}\right.$ max measured via indirect calorimetry) of breast cancer survivors.

\section{Methods}

\section{Trial design}

The current study is a two-armed, parallel design randomised

120 controlled trial that compares a six month home-based PA intervention to usual care in post-adjuvant breast cancer survivors that represents a substudy within a larger parent trial (Lahart, Metsios, Nevill, Kitas, \& Carmichael, 2016) (NCT02408107). The present study includes additional outcomes not included in the parent publication, including a direct measure of cardiorespiratory fitness, and cardiovascular outcomes (heart rate peak and resting heart rate, systolic and diastolic blood pressure, and mean arterial pressure). All measurements were recorded at baseline before randomization and after the six-month intervention. The study was approved by the Black Country NHS Ethics Committee. All participants provided written consent prior to data collection.

\section{Participants}

Forty per cent ( $n=32 / 80$ ) of the patients randomised to intervention and usual care groups in the parent study were also randomised to the substudy. Women attending breast cancer clinics at Russells Hall Hospital (The Dudley Group NHS Foundation Trust, UK), were invited to enrol in the study by the breast team, which included consultant and specialist nurses, between January 2010 and March 2013. Interested patients were given a study information booklet and were contacted by the primary researcher via telephone a week later. Participants were eligible to participate if they were: 1) females aged 18-72 years, 2) diagnosed with invasive breast cancer (Stage I-III) within two years of enrolment, 3) post-surgery and had no surgery planned for the next six months at least, 4) had fully completed adjuvant therapy (radiotherapy and/or chemotherapy) not including hormonal therapy, 5) no previous malignancy, 6) consent to be randomised 7) and willing to maintain contact with the investigators over the six months. Exclusion criteria included: 1) inability to participate in PA because of severe disability (e.g., severe arthritic conditions), 2) psychiatric illness and 3) vulnerable subjects, such as pregnant women or any other patient where PA was not approved by their oncologist due to the presence of one or more contraindications to exercise in cancer patients (American College of Sports Medicine [ACSM], 2013). Participants who self-defined as physically active at the time of enrolment were not excluded from participation.

\section{Home-based PA intervention}

Following consent and randomisation, breast cancer patients in the intervention group received an intervention aimed at encouraging the adoption of a more physically active lifestyle. Participants received a 30-45 min face-to-face consultation, followed by a support telephone call at the end of months one, two and three. During each of the last two months (4 and 5) patients received a mailed PA reminder leaflet encouraging their participation in home-based PA. The face-to-face consultation was based on the four core motivational interviewing principles: expressing empathy, developing discrepancy, rolling with resistance, and supporting self-efficacy (Miller \& Rollnick, 2013; Rosengren, 2009). To ensure consistency in intervention delivery across sessions and participants, a semistructured motivational interviewing-based intervention protocol was developed to guide intervention delivery. The topics covered in the 30-45 min consultation were similar to other trials (Baruth, Wilcox, Der Ananian, \& Heiney, 2015; Matthews et al., 2007; Pinto et al., 2005; Rogers et al., 2009) that incorporated a PA counselling component, including: current PA behaviour, decision balance exercise; benefits of PA in general and specific to breast cancer survivors; perceived barriers; prompts to seek social support, goal setting, types and intensities of PA (e.g., explanation of light, moderate and vigorous PA with examples specific to participants, such as taking a brisk walk so that you are mildly breathless but can still hold a conversation); safety advice. We also provided basic lifestyle 
information such as basic dietary information, portion size, fat intake, smoking, and hydration in generally and during PA.

The initial goal of the intervention (months 1-3) was for participants to progress towards accumulating 30 minutes of moderate-intensity PA on three to five days per week. Participants were allowed to choose the mode of PA they performed during the intervention, with walking and aerobic exercise strongly recommended by the researchers. During months 3 to 6 , the intervention participants were encouraged to work towards accumulating at least 30 minutes of moderate-intensity PA on five to seven days per week in broad agreement with current public health guidelines (Bull \& Expert Working Groups, 2010). If participants were already achieving this on trial entry they were, as a minimum, actively encouraged to maintain their level of PA. The focus of the follow-up phone calls (end of months 1-3) was to prevent relapse back to inactivity and/or improve maintenance of PA (accumulate $30 \mathrm{~min}$ of moderateintensity PA on 3-5 days/week), covering topics similar to the face-to-face consultation. Calls lasted approximately 15-20 min and were guided by a standardised phone call script. Participants were encouraged to telephone the research team should they encounter any problems or relapse in their efforts to increase their PA. Therefore, our intervention represented a pragmatic step down approach (i.e., from in-person sessions to telephone calls to postcard prompts), that could feasibly be employed by cancer-care nurses in routine clinical practice. Participants were also given a PA pack consisting of an information booklet and a DVD (previously developed by Breast Cancer Care) that provided further information of topics such as exercising safety, exercise intensity, dealing with fatigue and exercising with lymphedema. Information about local physical activity opportunities was also provided, including an exercise initiative run in local parks. During the intervention period, participants were encouraged, but not required to keep PA diaries to check whether they were achieving $150 \mathrm{~min}$ of moderate-vigorous PA over each week. Participants were advised to refrain from activity if they experienced any problems relating to the PA intervention (e.g., chest pain or developed a joint problem). If these circumstances occurred, patients would have been advised to contact the clinical team, and the clinician of the research team would have made a clinical decision based on the contraindications and precautions to PA for patients with cancer as to whether the patient refrained from PA temporarily or withdrew from the intervention (ACSM, 2013).

\section{Usual care group}

Since not informing patients about the benefits of PA may be considered unethical, participants randomised to the usual care arm were told standard information regarding PA (i.e., the current recommended PA guidelines), as provided to all breast cancer patients treated at the site. The usual care group did not receive guidance on how to meet the recommended PA guidelines. Participants completed the same baseline and

240 post-six month intervention assessments as the PA intervention group. After completion of the intervention, participants in the usual care group were encouraged to adopt a more physically active lifestyle and were given the same guidance and physical activity pack as the intervention group.
Study outcomes

The primary outcome of the current substudy was cardiorespiratory fitness $\left(\mathrm{V}_{2} \mathrm{max}\right)$. Secondary outcomes included exercise tolerance test variables, time to exhaustion (TTE) and peak heart rate (HR peak); resting cardiovascular measures, resting HR (RHR), systolic and diastolic blood pressure $(\mathrm{BP})$, and mean arterial pressure (MAP); self-reported physical activity outcomes via International PA Questionnaire (IPAQ, included total, walking, moderate, and vigorous PA in METmin. $\mathrm{wk}^{-1}$; and anthropometric (body mass and BMI) measures. All assessments were made at baseline and within two weeks of completing the six-month intervention. All participants were subjected to the same data collection procedures overseen by investigators (exercise physiologists) who were not blinded to group allocation.

\section{Exercise tolerance and cardiovascular outcomes}

Exercise tolerance tests were performed on a treadmill (H/P/ Cosmos, Pulsar, Nussdorf-Traunstein, Germany) using the validated Bruce test protocol (Bruce, Blackmon, Jones, \& Strait, 1963). The Bruce test was started at $2.74 \mathrm{~km} \cdot \mathrm{h}^{-1}\left(1.7 \mathrm{~m} \cdot \mathrm{h}^{-1}\right)$ and at incline of $10 \%$ for three minutes. At three minute intervals the incline of treadmill increased by $2 \%$ and speed increase to 4.02 , $5.47,6.76,8.05,8.85,9.65,10.46,11.26$ and $12.07 \mathrm{~km} \cdot \mathrm{h}^{-1}$ in each stage (10 stages in total), respectively. Ventilatory gas exchange was determined using a calibrated breath-by-breath system (Metalyzer 3B, Cortex Biophysik GmbH, Leipzig, Germany) allowing continuous measurement of gas variables, including $\dot{V} \mathrm{O}_{2}, \dot{V} \mathrm{CO}_{2}$, minute ventilation, and respiratory exchange ratio (RER). Moreover, during the test heart rate was also monitored using a heart rate monitor and strap (Polar USA, Woodbury, NY). Testing was terminated when the participant reached voluntary exhaustion. The test was also discontinued if the participants showed signs of sudden paleness, rapid change in HR, dizziness or cold sweat (none of the participants experienced any of these symptoms). $\dot{V} \mathrm{O}_{2}$ max was determined by taking the highest $\dot{\mathrm{V}} \mathrm{O}_{2}$ value averaged over a 20 -s period during the test. To determine whether a maximal effort was achieved the following secondary criteria were used: $\dot{V} \mathrm{O}_{2}$ plateau (change in $\dot{V} \mathrm{O}_{2} \leq 50 \mathrm{ml} / \mathrm{min}$ ), $\mathrm{RER} \geq 1.10$ and $\mathrm{HR}$ peak within $10 \mathrm{bpm}$ of the age-predicted maximum (220 age) (Astorino, Robergs, Ghiasvand, Marks, \& Burns, 2000).

Prior to performing the exercise tolerance test, RHR and BP was assessed three times on the brachial artery using a Datascope Accutorr Plus (Datascope, Montvale, NJ, USA), while the participant was resting in a seated position. Patients were given five minutes of sitting at rest before the first BP measurement was taken. Both the exercise tolerance and BP assessments were conducted in controlled conditions in the cardiovascular laboratory of the Research and Development Unit of the hospital on a separate day to the other outcome measurements.

\section{Physical activity and anthropometric outcomes}

Participants completed the validated IPAQ-long form questionnaire, which assesses the duration (number of days $\mathrm{x}$ min per day) that an individual has engaged in walking, moderate, and 
vigorous PA across four domains (occupational, active transportation, domestic, and leisure) over the past seven days (Craig et al., 2003). PA data were then used to calculate the MET-based IPAQ score by weighting each type of activity by its MET energy requirement (3.3 $x$ walking duration; $4 x$ moderate PA duration; 8 $x$ vigorous PA duration). Data were summed across activity domains to produce a weighted estimate of total PA (primary outcome) from all reported activities per week (MET-min·wk ${ }^{-1}$ ), as well as a subtotal of activity for each of the four domains, as well as walking, moderate and vigorous PA. The IPAQ has good reliability (Spearman's rho $=.8$ ) and moderate concurrent validity

310 (Spearman's rho $=.33$ ) when compared to accelerometer data (Spearman's rho $=.33$ ) (Craig et al., 2003).

Body mass was also measured via the Tanita BC-418 MA Analyser (Tanita Corporation, Tokyo, Japan), and was recorded to the nearest $.1 \mathrm{~kg}$. Standing height was measured without shoes to the nearest $.5 \mathrm{~cm}$ on a portable stadiometer (Seca 214 Road Rod, Seca gmbh \& co. kg., Hamburg, Germany). BMI $\left(\mathrm{kg} \cdot \mathrm{m}^{2}\right)$ was calculated on the basis of measured height and mass (mass in $\mathrm{kg}$ multiplied by height in $\mathrm{m}$ squared).

\section{Sample size calculation and randomisation}

320 Power calculations for the parent study, based on total PA as the primary outcome, estimated that at least 36 participants in each group ( $N=72$ ) would be required, using a betweengroup mean $(s)$ change in self-reported PA of 16.5 (25.1) MET$\mathrm{h} \cdot \mathrm{wk}^{-1}$ found in a similar trial (Matthews et al., 2007). Sample sizes were estimated with a spreadsheet developed by Hopkins (2006) using data extracted from a recent similar study (Courneya et al., 2003). This method requires sample sizes approximately one-third or lower than those of traditional methods. Assuming a change in $\dot{V}_{2}$ max of $3.4 \mathrm{ml} / \mathrm{kg} /$ min with a within-subject SD of $1.55 \mathrm{ml} / \mathrm{kg} / \mathrm{min}$, we needed a total of 6 participants. Using a traditional method of sample size calculation ( $5 \%$ alpha and $20 \%$ beta), we needed a total of 15 participants (i.e., 8 per group) to detect a $3.4 \mathrm{ml} / \mathrm{kg} / \mathrm{min}$ change in $\dot{V}_{2}$ max (within-subject SD of $1.55 \mathrm{ml} / \mathrm{kg} / \mathrm{min}$ ). Due to available resources, we randomised $40 \%$ of the parent sample (32 participants, 16 in each group) to our substudy sample. At a Clinic Trials Unit on a different site, a computer generated random numbers list was used to allocate all participants into intervention or usual care groups (concealed from the primary researcher), and the same sequence was used to allocate $40 \%(n=32 / 80)$ of participants in each group into the current substudy. Patients were allocated to intervention and usual care groups on a 1:1 allocation ratio and were stratified based on adjuvant chemotherapy.

\section{Statistical analysis}

We investigated pre-post-intervention differences between the intervention and usual care groups using a contemporary magnitude-based inferences approach (Batterham \& Hopkins, 2006). In this approach, mean effects of the PA intervention and their $90 \%$

350 confidence limits were estimated with a spreadsheet (Hopkins, AQ9 scores between baseline and post-intervention in the two groups

and adjusted for baseline values of each outcome. Each participant's change score was expressed as a percentage of baseline score via analysis of log-transformed values, to reduce bias arising from non-uniformity of error. For this approach, effect sizes were calculated by dividing the log-transformed mean differences between intervention and usual care groups divided by the pooled log-transformed baseline $s$ of outcomes. The spreadsheet also computed quantitative and qualitative chances that the true effects were beneficial, trivial, and harmful when a value for the smallest meaningful change was entered. A Cohen unit of .2 was employed as the smallest meaningful change in outcomes (Cohen, 1988). Where the chance of benefit and harm are both $>5 \%$, the effect is deemed unclear. Qualitative descriptors were then assigned to the quantitative percentile scores as follows: $25-75 \%$ possible, 75-95 \% likely, and >99 \% most likely. Effect sizes of $<.20$ were interpreted as trivial, .2 to.59 as small, .6 to 1.19 as moderate, and $\geq 1.2$ as large (Hopkins, Marshall, Batterham, \& Hanin, 2009). ${ }^{33}$ To further enhance the practical application of the findings, we calculated Cohen's $U_{3}$ index, an index used to determine the percentile gain in an intervention group (Durlak, 2009). ${ }^{34}$ For example, a Cohen's $d$ of .50 suggests that, on average, a participant in the intervention group would be at approximately the 69th percentile in terms of improving a particular outcome measure (or is 19\% higher than average control group participant).

As recommended for small samples, we used the Process macro for SPSS to perform nonparametric bootstrapping analyses (Hayes, 2013; Preacher, Rucker, \& Hayes, 2007) to test the mediational model of body mass $(\mathrm{kg})$ as a mediator of the relationship between group allocation (PA intervention or usual care) and relative $\dot{V} \mathrm{O}_{2} \max \left(\mathrm{ml} \cdot \mathrm{kg}^{-1} \cdot \mathrm{min}^{-1}\right)$. In these analyses, mediation is significant if the $95 \%$ Bias Corrected and accelerated confidence intervals ( $\mathrm{BCa} 95 \% \mathrm{Cl}$ ) for the indirect effect do not include zero (Preacher et al., 2007).

\section{Results}

\section{Flow of participants through the trial and recruitment}

Forty participants each were randomised to the intervention and usual care groups of the parent study and of the forty participants in each group $40 \%$ (16 in each group) were randomly allocated to the cardiorespiratory fitness substudy presented here. Twenty nine of the substudy participants completed the trial, with 15 and 14 completers in the intervention group and usual care group, respectively. One participant discontinued the intervention due to breast cancer recurrence and two participants dropped out of the usual care group due to not wanting to come back to the hospital for post-intervention testing. Flow of participants through the study is provided in Figure 1.

\section{Participant characteristics at baseline}

Table 1 provides the baseline characteristics of the 32 study participants (height $=162 \pm 5.4 \mathrm{~cm}$; mass $=70.6 \pm 10.3 \mathrm{~kg}$; $\mathrm{BMI}=27.2 \pm 4.4 \mathrm{~kg} \cdot \mathrm{m}^{2}$ ). Eight $(50 \%)$ participants in each group had undergone chemotherapy. The baseline characteristics of participants in the intervention and usual care groups were 


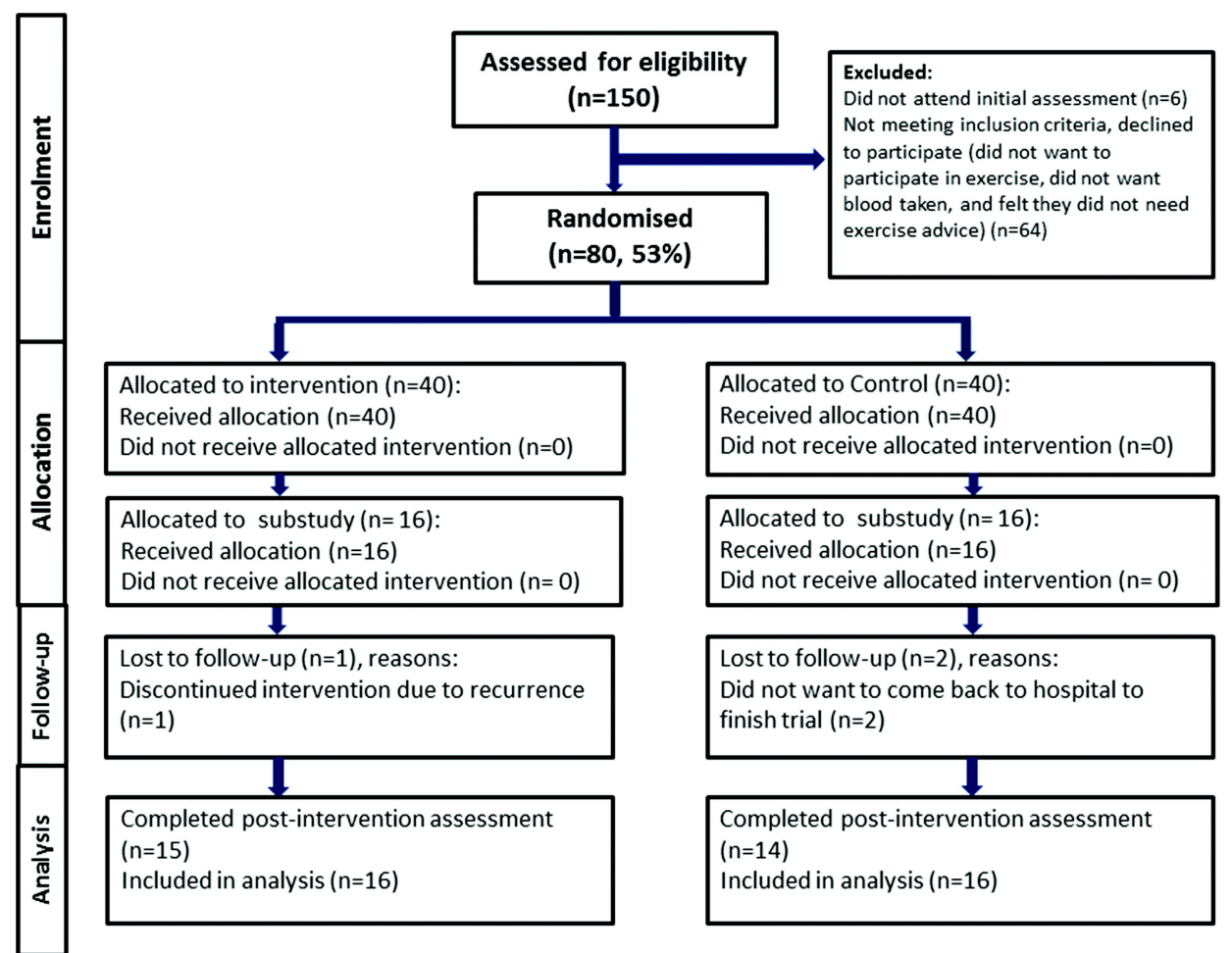

Figure 1. Flow of participants through the study.

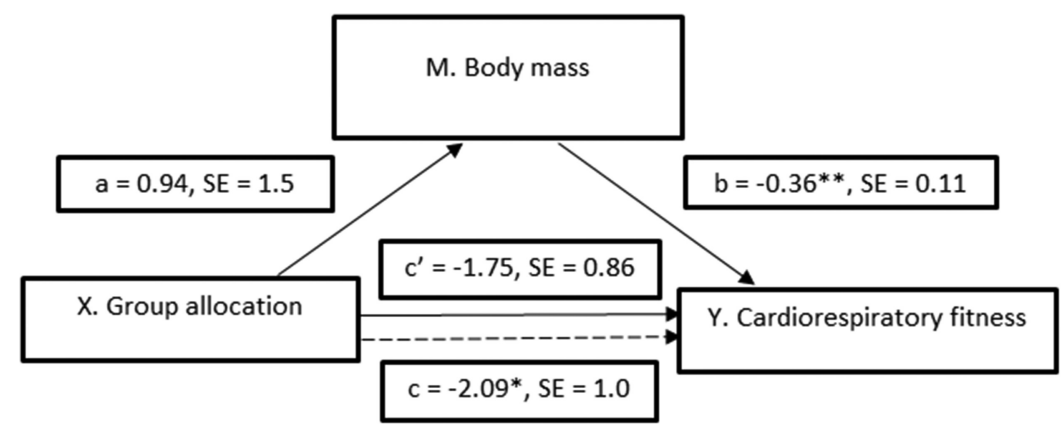

Figure 2. Path unstandardized coefficients and standard errors (SE) for simple mediation analysis of relationship between group allocation (X) and cardiorespiratory fitness $(Y)$ as mediated by body mass $(M)$. Note: Dotted line denotes the effect of group allocation on cardiorespiratory fitness when body weight is not included as a mediator ( $c=$ total effect).

similar in terms of age, mean time since diagnosis and end of treatment, and other demographic and lifestyle factors (Table 1).

\section{Exercise tolerance test and resting cardiovascular outcomes}

410 Baseline and post-intervention values for outcomes are provided in Table 2. At baseline, mean relative $\dot{\mathrm{VO}}_{2}$ max for all participants tested was $25.3 \pm 4.7 \mathrm{ml} \cdot \mathrm{kg}^{-1} \cdot \mathrm{min}^{-1}$. In accordance with age and gender matched normative values, consistent with the American College of Sports Medicine ${ }^{22}$, the median percentile of $20 \mathrm{ml} \cdot \mathrm{kg}$ ${ }^{-1} \cdot \mathrm{min}^{-1}$ corresponded to the "poor" category for cardiorespiratory fitness. Regarding criteria for maximal efforts, a plateau in $\dot{\mathrm{V}} \mathrm{O}_{2}$ was achieved in all participants apart from one participant in the usual care at baseline and one participants in the intervention group post-intervention, an RER of $\geq 1.1$ was achieved by all participants, and, HR peak within $10 \mathrm{~b} / \mathrm{min}$ of the age-predicted maximum was achieved in all apart from two participants at baseline ( 1 each in intervention and usual care) and in participants three ( 1 in intervention, and 2 in usual care) post-intervention. All participants met either the $\dot{V} \mathrm{O}_{2}, \mathrm{RER}$, or HRpeak criteria at both baseline and post-intervention.

The magnitude-based inference (adjusted for baseline levels) analysis revealed the effect of the PA intervention was likely to have been beneficial ( $85 \%$ likelihood of a beneficial effect) on relative $\dot{V}_{2}$ max, compared with the usual care (see Table 3). In addition, given the Cohen's $d$ value, $67 \%$ of the intervention group will be above the mean of the usual care group (i.e., Cohen's $U_{3}$ represents a $17 \%$ gain in the intervention group). The effect of the intervention on absolute $\dot{V}_{2}$ max was also likely beneficial ( $82 \%$ likelihood of a beneficial effect, see Table 3). Given the Cohen's $d$ value, $66 \%$ of the intervention group will be above the mean of 
Table 1. Personal characteristics of the participants at baseline (intervention, $\mathrm{n}=16$; usual care, $\mathrm{n}=16$ ).

\begin{tabular}{|c|c|c|c|}
\hline & $\begin{array}{l}\mathrm{N}(\%) \\
\text { overall }\end{array}$ & $\begin{array}{l}\mathrm{N}(\%) \\
\text { intervention }\end{array}$ & $\begin{array}{l}\mathrm{N}(\%) \text { usual } \\
\text { care }\end{array}$ \\
\hline Mean $\pm s$ age (years) & $52.3 \pm 9.6$ & $52.5 \pm 10.7$ & $52.0 \pm 8.6$ \\
\hline $\begin{array}{l}\text { Mean } \pm s \text { time since diagnosis } \\
\text { (week) }\end{array}$ & $40.6 \pm 24.5$ & $41.3 \pm 25.5$ & $39.9 \pm 25.4$ \\
\hline $\begin{array}{l}\text { Mean } \pm s \text { weeks since end of } \\
\text { treatment }\end{array}$ & $10.9 \pm 9.2$ & $10.1 \pm 9.4$ & $11.6 \pm 11.6$ \\
\hline \multicolumn{4}{|l|}{ Ethnic Origin } \\
\hline \multirow{2}{*}{\multicolumn{4}{|c|}{$\operatorname{BMI}\left(\mathrm{kg} / \mathrm{m}^{2}\right)$}} \\
\hline & & & \\
\hline Obese (BMI $\geq 30$ ) & $8(25)$ & $5(31)$ & $3(19)$ \\
\hline Overweight (BMI 25-29.9) & $12(38)$ & $6(38)$ & $4(25)$ \\
\hline Normal (BMI 18-24.9) & $12(38)$ & $5(31)$ & 7 (44) \\
\hline Underweight $(\mathrm{BMI}<18)$ & $0(0)$ & $0(0)$ & $0(0)$ \\
\hline \multicolumn{4}{|l|}{ Family History of breast cancer } \\
\hline Yes & $6(19)$ & $3(19)$ & $3(19)$ \\
\hline No & $26(81)$ & $13(81)$ & $13(81)$ \\
\hline \multicolumn{4}{|l|}{ Smoking: } \\
\hline Ever & $12(38)$ & $2(13)$ & $10(50)$ \\
\hline Never & $20(63)$ & $14(70)$ & $6(38)$ \\
\hline \multicolumn{4}{|l|}{ Alcohol drinkers } \\
\hline Yes & $25(78)$ & $11(69)$ & $14(88)$ \\
\hline No & $7(22)$ & $5(31)$ & $2(12)$ \\
\hline \multicolumn{4}{|l|}{ Co-morbidities: } \\
\hline Diabetes & $1(3)$ & $1(6)$ & $0(0)$ \\
\hline Hypertension & $4(13)$ & $3(18)$ & $1(6)$ \\
\hline High Cholesterol & $3(9)$ & $2(13)$ & $1(6)$ \\
\hline Heart disease & $2(6)$ & $1(6)$ & $1(6)$ \\
\hline Vascular disease & $1(3)$ & $0(0)$ & $1(6)$ \\
\hline Asthma or chronic bronchitis & $4(13)$ & $1(6)$ & $3(18)$ \\
\hline Osteoarthritis & $6(19)$ & $2(13)$ & $4(25)$ \\
\hline Rheumatoid arthritis & $2(6)$ & $1(6)$ & $1(6)$ \\
\hline Kidney disease & $2(6)$ & $0(0)$ & $2(13)$ \\
\hline Liver disease & $1(3)$ & $0(0)$ & $1(6)$ \\
\hline Currently menstruating & $7(22)$ & $3(19)$ & $4(25)$ \\
\hline $\begin{array}{l}\text { Yes } \\
\text { No }\end{array}$ & $25(78)$ & $13(81)$ & $12(75)$ \\
\hline \multicolumn{4}{|l|}{ No } \\
\hline Marital Status & $27(84)$ & $15(94)$ & $12(75)$ \\
\hline $\begin{array}{l}\text { Married/living with partner } \\
\text { Not married }\end{array}$ & $5(16)$ & $1(6)$ & $4(25)$ \\
\hline $\begin{array}{l}\text { Education } \\
\text { Mean age } \pm s \text { years leaving } \\
\text { school }\end{array}$ & $16.9 \pm 2.0$ & $16.6 \pm 1.9$ & $17.1 \pm 2.2$ \\
\hline $\begin{array}{l}\text { Employment status } \\
\text { Employed full-time/part-time }\end{array}$ & $17(53)$ & $9(56)$ & $8(50)$ \\
\hline \multicolumn{4}{|l|}{ Physical activity (IPAQ categories) } \\
\hline Low & $9(28)$ & $4(25)$ & $5(31)$ \\
\hline Moderate & $19(59)$ & $12(75)$ & $7(44)$ \\
\hline High & $4(13)$ & 0 & $4(25)$ \\
\hline
\end{tabular}

the usual care group (i.e., $C o h e n ' s U_{3}$ represents a $16 \%$ gain in the intervention group). The magnitude-inference approach revealed no likely beneficial effects of the intervention on any of the exercise tolerance or resting cardiovascular health outcomes, and the $90 \% \mathrm{Cl}$ for each of the effect sizes contained zero. Baseline and post-intervention treadmill test RER values were similar in both groups (intervention, baseline: $1.37 \pm 0.14$, post: $1.37 \pm 0.11$; usual care, baseline: $1.34 \pm 0.10$, post: $1.36 \pm 0.09$ ).

\section{Physical activity and anthropometric outcomes}

445 Based on the magnitude-based inferences approach, for those who completed the trial, the effect of the intervention was likely beneficial on total PA and moderate PA $(91 \%$ and $82 \%$ likelihood of a beneficial effect, respectively) compared to usual care. Based on the effect sizes, $76 \%$ of the total PA and
Table 2. Baseline and post-intervention data for exercise tolerance test, body mass and physical activity (PA, MET-min.week) variables ${ }^{\dagger}$

\begin{tabular}{|c|c|c|c|c|}
\hline & \multicolumn{2}{|c|}{ Intervention group } & \multicolumn{2}{|c|}{ Usual care group } \\
\hline & Baseline & $\begin{array}{c}\text { Post- } \\
\text { intervention }\end{array}$ & Baseline & $\begin{array}{l}\text { Post- } \\
\text { intervention }\end{array}$ \\
\hline $\begin{array}{l}\dot{\mathrm{VO}_{2} \max } \\
\quad\left(\mathrm{ml} \cdot \mathrm{min}^{-1}\right)\end{array}$ & $1713 \pm 318$ & $1834 \pm 296$ & $1816 \pm 264$ & $1852 \pm 223$ \\
\hline $\begin{array}{l}\dot{\mathrm{VO}_{2} \max } \\
\quad\left(\mathrm{ml} \cdot \mathrm{kg}^{-1} \cdot \mathrm{min}^{-1}\right)\end{array}$ & $24.1 \pm 4.8$ & $26.2 \pm 5.3$ & $26.6 \pm 4.4$ & $26.6 \pm 3.3$ \\
\hline $\begin{array}{l}\text { Time to } \\
\quad \text { Exhaustion (sec) }\end{array}$ & $471 \pm 105$ & $531 \pm 100$ & $523 \pm 76$ & $545 \pm 49$ \\
\hline $\begin{array}{l}\text { Peak Heart rate } \\
\text { (bpm) }\end{array}$ & $176 \pm 11$ & $181 \pm 9$ & $174 \pm 14$ & $174 \pm 16$ \\
\hline $\begin{array}{l}\text { Resting SBP } \\
\qquad\left(\mathrm{mm} \cdot \mathrm{Hg}^{-1}\right)\end{array}$ & $125 \pm 10$ & $126 \pm 14$ & $127 \pm 13$ & $126 \pm 12$ \\
\hline $\begin{array}{l}\text { Resting DBP } \\
\left(\mathrm{mm} \cdot \mathrm{Hg}^{-1}\right)\end{array}$ & $78 \pm 6$ & $78 \pm 8$ & $82 \pm 8$ & $80 \pm 6$ \\
\hline $\begin{array}{l}\text { Resting MAP } \\
\left(\mathrm{mm} \cdot \mathrm{Hg}^{-1}\right)\end{array}$ & $97 \pm 10$ & $98 \pm 14$ & $99 \pm 11$ & $96 \pm 9$ \\
\hline Mass $(\mathrm{kg})$ & $72.2 \pm 12.0$ & $71.0 \pm 12.7$ & $69.0 \pm 8.3$ & $70.1 \pm 7.0$ \\
\hline Total PA & 604 (1058) & $1388(661)$ & $1313(2023)$ & 1497 (1623) \\
\hline Leisure PA & 308 (569) & 792 (572) & $428(930)$ & 594 (896) \\
\hline Walk PA & 404 (637) & 752 (726) & 347 (404) & $545(743)$ \\
\hline Moderate PA & 202 (961) & $586(636)$ & $599(946)$ & 819 (1651) \\
\hline Vigorous PA & $0(0)$ & $0(320)$ & $0(270)$ & $0(180)$ \\
\hline
\end{tabular}

Descriptive statistics presented as either mean \pm SD or median (interquartile range) depending on distribution of data;

tPost-intervention data were only available for the 15 participants in the intervention and the 14 participants in the usual care.

be above the mean of the usual care group (i.e., using Cohen's $\mathrm{U}_{3}$ Index, the percentile increase in the intervention group was $26 \%$ and $22 \%$, respectively). The effect of the intervention on vigorous PA levels was unclear. This lack of a clear effect likely reflects the fact that nine participants in the intervention group and six in the usual care group reported no vigorous PA at both baseline and post-intervention, one participant in the intervention group and four in the usual care group reduced vigorous $\mathrm{PA}$, while five intervention group and four usual care participants increased their vigorous PA. No association was found between pre-post-intervention changes in relative $\dot{V O}_{2}$ max and changes in self-reported moderate-tovigorous $\mathrm{PA}(r=.16, p=.45)$.

\section{Mediation analysis of the effect of PA intervention on cardiorespiratory fitness through body mass}

The total effect of group allocation on cardiorespiratory fitness was significant, $c=-2.09, t(27)=-2.09, p<.05$; allocation to usual care group predicted an approximate $2 \mathrm{ml} \cdot \mathrm{kg}^{-1} \cdot \mathrm{min}^{-1}$ decrease in cardiorespiratory fitness. Group allocation was not significantly predictive of the hypothesized mediating variable, body mass; $a=.939, t(27)=.627, p>.05$. When controlling for group allocation, body mass was significantly predictive of cardiorespiratory fitness, $b=-.365, t$ (26) $=-3.34, p<.01$. The estimated direct effect of group allocation on cardiorespiratory fitness, controlling for body mass, was $c^{\prime}=-1.75, t(26)=-2.04, p>.05$. Figure 2 shows the unstandardized path coefficients for this mediation analysis. Cardiorespiratory fitness was not well predicted from group allocation and body mass, with adjusted $R^{2}=.4$ and $F$ $(2,26)=8.58, p<.01$. However, the indirect effect of group allocation on cardiorespiratory fitness through body mass was not significant, $a b=-.34$, BCa bootstrapped $95 \% \mathrm{Cl}=-1.32$ to 
Table 3. Magnitude-based inference analysis of changes in cardiorespiratory fitness $\left(\mathrm{V}_{2}\right.$ max) and additional exercise tolerance test variables, physical activity (PA), and anthropometric measures in intervention and usual care groups and qualitative inferences about the intervention effects (all PA data reported as MET-min.wk ${ }^{-1}$ ).

\begin{tabular}{|c|c|c|c|c|c|}
\hline \multirow[b]{2}{*}{ Variable } & \multicolumn{3}{|c|}{ Change in Measure (\%) from Baseline to Post-intervention } & \multirow[b]{2}{*}{$\begin{array}{l}\text { Effect Size }(d) \\
\quad(90 \% \mathrm{Cl})\end{array}$} & \multirow[b]{2}{*}{$\begin{array}{c}\text { Qualitative inference (\% likelihood } \\
\text { of at least a small effect) }\end{array}$} \\
\hline & $\begin{array}{l}\text { Intervention mean } \\
\text { (s as a CV) }\end{array}$ & $\begin{array}{l}\text { Usual care mean } \\
\text { (s as a CV) }\end{array}$ & $\begin{array}{l}\text { Between group difference in means } \\
\qquad(90 \% \mathrm{Cl})\end{array}$ & & \\
\hline$\dot{\mathrm{V}} \mathrm{O}_{2} \max \left(\mathrm{ml} \cdot \mathrm{min}^{-1}\right)$ & $5.8(11.7)$ & $-0.8(8.1)$ & 6.7 (.5 to 13.3$)$ & .40 (.03 to .77$)$ & Likely beneficial (82\%) \\
\hline$\dot{V} O \max \left(\mathrm{ml} \cdot \mathrm{kg}^{-1} \cdot \mathrm{min}^{-1}\right)$ & $7.7(12.0)$ & $-0.2(10.4)$ & 7.9 (.8 to 15.4$)$ & $.44(.05$ to .83$)$ & Likely beneficial (85\%) \\
\hline TTE (sec) & $12.7(20.0)$ & $4.9(11.2)$ & $7.5(-2.2$ to 18.1$)$ & $.37(-.12$ to .86$)$ & Possibly beneficial (72\%) \\
\hline HR peak (bpm) & $2.2(4.9)$ & $-0.2(3.1)$ & $2.4(-.1$ to 5.0$)$ & $.32(-.02$ to .65$)$ & Possibly harmful (72\%) \\
\hline $\mathrm{HR}$ rest (bpm) & $-5.6(9.5)$ & $-8.0(12.3)$ & $2.5(-4.1$ to 9.6$)$ & $.20(-.33$ to .72$)$ & Unclear \\
\hline SBP rest $(\mathrm{mmHg})$ & $1.1(10.9)$ & $-1.4(5.2)$ & $2.5(-2.7$ to 7.9$)$ & $.25(-.28$ to .77$)$ & Unclear \\
\hline DBP rest $(\mathrm{mmHg})$ & $1.2(8.7)$ & $-2.4(6.9)$ & $3.7(-1.0$ to 8.8$)$ & $.39(-.12$ to .91$)$ & Possibly harmful (73\%) \\
\hline MAP rest $(\mathrm{mmHg})$ & $.7(12.4)$ & $-3.4(7.5)$ & $4.3(-1.9$ to 10.9$)$ & $.35(-.16$ to .87$)$ & Possibly harmful (69\%) \\
\hline Total PA & $79.8(74.6)$ & $4.6(151.3)$ & 71.9 (5.2 to 180.8$)$ & $.73(.07$ to 1.40$)$ & Likely beneficial (91\%) \\
\hline Walking PA & $-11.9(1141.5)$ & $31.1(994.6)$ & $-32.8(-85.8$ to 218.3$)$ & $-.22(-1.08$ to .64$)$ & Unclear \\
\hline Moderate PA & $116.1(505.9)$ & $-29.4(938.2)$ & $206.0(-19.3$ to 1061.2$)$ & $.59(-.11$ to 1.28$)$ & Likely beneficial (82\%) \\
\hline Vigorous PA & $399.2(3067.3)$ & $-11.2(8853.4)$ & $462.1(-56.2$ to 7171.5$)$ & $.64(-.31$ to 1.59$)$ & Unclear \\
\hline Mass (kg) & $-2.1(6.4)$ & $-.7(3.5)$ & $-1.4(-4.5$ to 1.7$)$ & $-.10(-.32$ to .12$)$ & Likely trivial (76\%) \\
\hline BMI $\left(\mathrm{kg} / \mathrm{m}^{2}\right)$ & $-2.2(6.1)$ & $-1.0(3.6)$ & $-1.2(-4.2$ to 1.9$)$ & $-.08(-.28$ to .12$)$ & Likely trivial (83\%) \\
\hline
\end{tabular}

Key: CV, coefficient of variation; $s$ indicates standard deviation; $95 \% \mathrm{Cl}, 95 \%$ confidence interval; ES, effect size (Cohen's d; effect estimate/pooled baseline s); VO $_{2}$ max, maximal oxygen uptake; TTE, time to exhaustion; HR, heart rate; SBP, systolic blood pressure; DBP, diastolic blood pressure; MAP, mean arterial pressure; BMI, body mass index.

Analysis based on 29 participants (intervention $=15$; usual care $=14$ ).

Beneficial effect reflects an increase in $\dot{V}_{2}$ max, TTE, and PA measures and a decrease in anthropometric and cardiovascular measures

.86. The ratio of indirect to total effect suggests that a relatively small part of the effect of group allocation (i.e., allocation to PA or usual care) on cardiorespiratory fitness is mediated by body mass, $\mathrm{P}_{\mathrm{M}}=.16$.

\section{Discussion}

In our sample of breast cancer survivors, magnitude-based inference analysis revealed "likely" at least small beneficial effects on both relative and absolute cardiorespiratory fitness, and total and moderate PA over the course of the intervention period in the intervention group compared to the usual care group. Furthermore, mediation analysis revealed that only a small proportion of the observed increases in $\mathrm{VO}_{2}$ max in the PA intervention group were mediated by changes in body mass. No "likely" beneficial effects of the intervention were found for any of the other exercise tolerance or resting cardiovascular health outcomes.

The mean $\dot{V}_{2}$ max values of the post-adjuvant therapy breast cancer survivors in this current study are similar to that reported in previous studies in which cardiorespiratory fitness was measured directly (Burnett, Kluding, Porter, Fabian, \& Klemp, 2013; Courneya et al., 2003; Dolan et al., 2015; Herrero et al., 2006; Hutnick et al., 2005; Irwin et al., 2014; Jones et al., 2012; Mehnert et al., 2011; Peel et al., 2009). The low $\mathrm{VO}_{2}$ max values reflect the poor physical condition of this cohort of breast cancer survivors. Their cardiopulmonary fitness levels were lower than the values associated with a threefold increase in risk of breast cancer mortality a previous study (Peel et al., 2009). Therefore, the values reported in the current study may indicate an increased risk of breast cancer mortality in our sample and the need for this population to improve cardiorespiratory fitness and overall health status.

We found increases in relative $\dot{V} \mathrm{O}_{2}$ max values of $7.7 \%$ in the PA intervention group, compared to no change $(-.2 \%)$ in the usual care group. This percentage change, represented a change realtive $\dot{V}_{2}$ max values of $1.87 \mathrm{ml} / \mathrm{kg} / \mathrm{min}$, which was less than the $3.5 \mathrm{ml} / \mathrm{kg} / \mathrm{min}$ ( $1 \mathrm{MET}$ ) change in cardiorespiratory fitness associated with significantly lower risk of breast cancer death (Peel et al., 2009). However, the magnitude of this treatment effect was within the $6.5 \%$ to $17 \%$ increases observed in previous studies assessing the effect of PA on $\dot{V}_{2}$ max in post-adjuvant therapy breast cancer survivors (Courneya et al., 2003; Dolan et al., 2015; Herrero et al., 2006; Hutnick et al., 2005; Irwin et al., 2014; Mehnert et al., 2011). Therefore, the improvements observed in cardiorespiratory fitness in the current study are encouraging given the homebased and moderate-intensity nature of the intervention. Improvements in relative $\dot{V}_{2}$ max can enhance the ability to perform activities of daily living, increase independence, promote a sense of well-being, and may ultimately confer a positive survival benefit (Herrero et al., 2006; Peel et al., 2009).

The lack of change in relative $\dot{V} \mathrm{O}_{2}$ max observed in the usual care group of the current study, despite a slight improvement in absolute $\dot{V}_{2}$ max, can almost entirely be attributed to a nonsignificant increase in body mass (i.e., the increase in absolute $\dot{V} \mathrm{O}_{2}$ max was equivalent to the increase in body mass). However, the increase in relative $\dot{V}_{2}$ max observed in the intervention group can only partially be explained by a reduction in body mass, given the improvements in absolute $\dot{V}_{2}$ max (i.e., the increase in relative $\mathrm{VO}_{2}$ max was higher than that expected for the reduction in body mass observed). Therefore, mechanisms other than reduced body mass may be responsible for the improvements in relative $\mathrm{VO}_{2}$ max observed in the intervention group. The mechanisms by which PA can increase $\mathrm{VO}_{2}$ max in breast cancer survivors remains to be elucidated. However, previous studies of postmenopausal women attributed PA-induced increases in $\mathrm{VO}_{2}$ max to adaptations in skeletal muscles (Spina, 1999; Spina, Ogawa, Miller, Kohrt, \& Ehsani, 1993). Adaptations associated with prolonged aerobic exercise, such as a greater left ventricular ejection fraction resulting from a more compliant cardiac chamber, capillary density, myoglobin concentrations, and muscle glycogen, facilitate improvements in cardiac output 
and arterial-venous oxygen difference, which can in turn improve $\dot{V}_{2} \max$ (Bassett \& Howley, 2000; Holloszy \& Coyle, 1984; Levine, 2008). Thus, it is plausible that both increases in cardiac output and arterial-venous oxygen difference contributed to the albeit small physiologic adaptations observed in this current trial. However, we found no association between prepost-intervention changes in relative $\dot{V O}_{2}$ max and changes in self-reported moderate-to-vigorous PA. We suggest that this lack of association may be attributed to the limitations of selfreported PA, such as misclassification, recall and social desirability biases (Shephard \& Vuillemin, 2003). In support of this suggestion, cardiorespiratory fitness is mainly, but not completely (due to genetic contributions), determined by recent PA patterns and is considered to be an objective measure of PA patterns that is superior to self-report (Blair, Cheng, \& Holder, 2001). Therefore, the assessment of self-reported previous 7-day PA may not have been sensitive enough to detect the changes in PA patterns required to induce the observed changes in $\dot{V}_{2}$ max. Furthermore, cardiorespiratory fitness may be a stronger predictor of health outcomes, including cancer mortality, than selfreported PA (Blair et al., 2001). Nevertheless, we cannot discount the possibility that psychological factors, such as increased motivation, self-confidence and tolerance, influenced the pre-post intervention changes in $\dot{V} \mathrm{O}_{2}$ max.

The limitations of our trial merit comment. Our small sample had an average age younger than is typical for women with a

580 breast cancer. The highest proportion of women diagnosed with breast cancer rates are aged 60 to 69 years (Cancer Research UK, 2006). Due to the non-blinding of the outcome assessor to the allocation of participants, we cannot rule out the possibility that performance bias influenced our results. Performance bias can be introduced if the outcome assessor consciously or unconsciously provided more encouragement during exercise tolerance tests to the participants in the intervention group than those in the usual care group, which may have resulted in more favourable scores in the intervention group. Although, indirect calorimetry is the gold

590 standard method of assessing $\dot{V}_{2} \mathrm{O}_{2}$ max, breath-by-breath systems can have a typical measurement error of approximately $\pm 2-3 \%$, and therefore, may account for a portion of the $\sim 8 \%$ improvement in $\dot{V}_{2}$ max observed in the intervention group (Robergs \& Burnett, 2003). However, every attempt was made to standardise 595 protocols across groups and the outcome assessor was carefully trained and monitored for objective and consistent administration of exercise test protocols. While attempts were made to reduce performance bias attributed to the outcome assessor, the blinding of participants to group allocation was not possible.

600 This inability to blind participants is an inherent limitation of PA studies, which may bias participant responses and behaviours because of their awareness of the study purpose and desire to please the research staff.

In the context of the limitations outlined above, we found 605 likely beneficial increases in relative and absolute cardiorespiratory fitness, and total and moderate PA in the intervention group compared to the usual care group. Our data highlight the potential effectiveness of a home-based PA intervention coupled with face-to-face counselling and telephone support in providing 610 beneficial effects on cardiorespiratory fitness, which may influence breast cancer outcomes and CVD risk. Large sample prospective longitudinal randomised controlled trials are needed to determine the impact of improvements in cardiorespiratory fitness on breast cancer outcomes and development of CVD in breast cancer survivors.

\section{Acknowledgments}

We would like to express gratitude to Dr Sarah Bowden and her team at the Birmingham Clinical Trials Unit for their support in randomisation, Russells Hall Hospital Breast Care Nurses for helping with recruitment, Russells Hall Hospital phlebotomy department and biochemistry laboratory for assistance with blood collection and analysis, and above all, each of the patients who contributed with their time and feedback to make this study possible.

\section{Disclosure statement}

No potential conflict of interest was reported by the authors.

\section{Funding}

This work was supported by the No funding was received. [NA].

\section{ORCID}

lan M. Lahart (D) http://orcid.org/0000-0003-1079-2876

Alan M. Nevill (D) http://orcid.org/0000-0003-0506-3652

George D. Kitas (D) http://orcid.org/0000-0002-0828-6176

George S. Metsios (D) http://orcid.org/0000-0001-5359-0436

\section{References}

American College of Sports Medicine. (2013). ACSM's guidelines for exercise testing and prescription (9th ed.). Philadelphia, PA: Lippincott Williams \& Wilkins.

Astorino, T. A., Robergs, R. A., Ghiasvand, F., Marks, D., \& Burns, S. (2000). Incidence of the oxygen plateau at VO2max during exercise testing to volitional fatigue. Journal of Exercise Physiologyonline, 3(4), 1-12.

Baruth, M., Wilcox, S., Der Ananian, C., \& Heiney, S. (2015). Effects of homebased walking on quality of life and fatigue outcomes in early stage breast cancer survivors: A 12-week pilot study. Journal of Physical Activity and Health, 12(Suppl 1), S110-118. doi:10.1123/jpah.2012-0339

Bassett, D. R., Jr., \& Howley, E. T. (2000). Limiting factors for maximum oxygen uptake and determinants of endurance performance. Medicine and Science in Sports and Exercise, 32(1), 70-84. doi:10.1097/00005768200001000-00012

Batterham, A. M., \& Hopkins, W. G. (2006). Making meaningful inferences about magnitudes. International Journal of Sports Physiology and Performance, 1(1), 50-57. doi:10.1123/ijspp.1.1.50

Blair, S. N. (1996). Influences of cardiorespiratory fitness and other precursors on cardiovascular disease and all-cause mortality in men and women. Journal of the American Medical Association, 276(3), 205-210. doi:10.1001/jama.1996.03540030039029

Blair, S. N., Cheng, Y., \& Holder, J. S. (2001). Is physical activity or physical fitness more important in defining health benefits? Medicine and Science in Sports and Exercise, $33(6$ Suppl), S379-399. doi:10.1097/ 00005768-200106001-00007

Bray, F., Ren, J.-S., Masuyer, E., \& Ferlay, J. (2012). Global estimates of cancer prevalence for 27 sites in the adult population in 2008 . International Journal of Cancer, 132(5), 1133-1145. doi:10.1002/ijc.27711

Bruce, R. A., Blackmon, J. R., Jones, J. W., \& Strait, G. (1963). Exercising testing in adult normal subjects and cardiac patients. Pediatrics, 32, 742-756.

Bull, F. C., \& Expert Working Groups. (2010). Physical activity guidelines in the UK: Review and recommendations. Loughborough: Loughborough University.
635 AQ15 
Burnett, D., Kluding, P., Porter, C., Fabian, C., \& Klemp, J. (2013). Cardiorespiratory fitness in breast cancer survivors. SpringerPlus, 2(1), 68. doi:10.1186/2193-1801-2-68

Cancer Research UK. (2006). Breast cancer incidence by age. Retrieved May, 2017, from http://www.cancerresearchuk.org/health-professional/ cancer-statistics/statistics-by-cancer-type/breast-cancer/incidence-inva sive\#heading-One

675 Chandra, D., Wise, R. A., Kulkarni, H. S., Benzo, R. P., Criner, G., Make, B., .. Sciurba, F. C. (2012). Optimizing the 6-Min walk test as a measure of exercise capacity in COPD. Chest, 142(6), 1545-1552. doi:10.1378/ chest.11-2702

Cohen, J. (1988). Statistical power analysis for the behavioral sciences (2nd ed.). Hillsdale, NJ: Lawrence Erlbaum Associates.

Courneya, K. S., Mackey, J. R., Bell, G. J., Jones, L. W., Field, C. J., \& Fairey, A. S. (2003). Randomized controlled trial of exercise training in postmenopausal breast cancer survivors: Cardiopulmonary and quality of life outcomes. Journal of Clinical Oncology, 21(9), 1660-1668. doi:10.1200/ JCO.2003.04.093

Craig, C. L., Marshall, A. L., Sjostrom, M., Bauman, A. E., Booth, M. L., Ainsworth, B. E., ... Oja, P. (2003). International physical activity questionnaire: 12-country reliability and validity. Medicine and Science in Sports and Exercise, 35(8), 1381-1395. doi:10.1249/01. MSS.0000078924.61453.FB

Dolan, L. B., Campbell, K., Gelmon, K., Neil-Sztramko, S., Holmes, D., \& McKenzie, D. C. (2015). Interval versus continuous aerobic exercise training in breast cancer survivors-A pilot RCT. Supportive Care in Cancer, 24(1), 119-127. doi:10.1007/s00520-015-2749-y

695 Durlak, J. A. (2009). How to select, calculate, and interpret effect sizes. Journal of Pediatric Psychology, 34(9), 917-928. doi:10.1093/jpepsy/ jsp004

Ekelund, U. (2008). Cardiorespiratory fitness, exercise capacity and physical activity in children: Are we measuring the right thing? Archives of Disease in Childhood, 93(6), 455-456. doi:10.1136/adc.2007.135202

Eloranta, S., Lambert, P. C., Andersson, T. M., Czene, K., Hall, P., Bjorkholm, M., \& Dickman, P. W. (2012). Partitioning of excess mortality in population-based cancer patient survival studies using flexible parametric survival models. BMC Medical Research Methodology, 12, 86. doi:10.1186/1471-2288-12-86

Ferlay, J., Soerjomataram, I., Dikshit, R., Eser, S., Mathers, C., Rebelo, M., ... Bray, F. (2014). Cancer incidence and mortality worldwide: Sources, methods and major patterns in GLOBOCAN 2012. International Journal of Cancer, 136(5), E359-E386. doi:10.1002/ijc.29210

710 Ferlay, J., Steliarova-Foucher, E., Lortet-Tieulent, J., Rosso, S., Coebergh, J. W. W., Comber, H., ... Bray, F. (2013). Cancer incidence and mortality patterns in Europe: Estimates for 40 countries in 2012. European Journal of Cancer, 49(6), 1374-1403. doi:10.1016/j.ejca.2012.12.027

Fillion, L., Gagnon, P., Leblond, F., Gélinas, C., Savard, J., Dupuis, R., ... Larochelle, M. (2008). A brief intervention for fatigue management in breast cancer survivors. Cancer Nursing, 31(2), 145-159. doi:10.1097/01. NCC.0000305698.97625.95

Fong, D. Y., Ho, J. W., Hui, B. P., Lee, A. M., Macfarlane, D. J., Leung, S. S., ... Cheng, K. K. (2012). Physical activity for cancer survivors: Meta-analysis of randomised controlled trials. BMJ (Clinical Research Ed.), 344,

Furmaniak, A. C., Menig, M., \& Markes, M. H. (2016). Exercise for women receiving adjuvant therapy for breast cancer. Cochrane Database of Systematic Reviews, 9, CD005001.

Hayes, A. F. (2013). Introduction to mediation, moderation, and conditional process analysis: A regression-based approach. New York, NY: Guilford Press.

Herrero, F., San Juan, A. F., Fleck, S. J., Balmer, J., Perez, M., Canete, S., ... Lucia, A. (2006). Combined aerobic and resistance training in breast cancer survivors: A randomized, controlled pilot trial. International Journal of Sports Medicine, 27(7), 573-580. doi:10.1055/s-2005-865848

Hoff, V., Layard, M. W., Basa, P., Davis, H. L., Rozencweig, M., \& Muggia, F. M. (1979). Risk factors for doxorubicin-induced congestive heart failure. Annals of Internal Medicine, 91(5), 710-717. doi:10.7326/0003-4819-915-710

Holloszy, J. O., \& Coyle, E. F. (1984). Adaptations of skeletal muscle to endurance exercise and their metabolic consequences. Journal of
Applied Physiology: Respiratory, Environmental and Exercise Physiology, 56(4), 831-838.

Hopkins, W. G. (2006a). Estimating sample size for magnitude-based inferences. Sportscience. 10, 63-70. http://www.sportsci.org/2006/wghss.htm

Hopkins, W. G. (2006b). Spreadsheets for analysis of controlled trials, with adjustment for a subject characteristic. Sportscience. 10, 46-50. http:// www.sportsci.org/2006/wghcontrial.htm

Hopkins, W. G., Marshall, S. W., Batterham, A. M., \& Hanin, J. (2009). Progressive statistics for studies in sports medicine and exercise science. Medicine and Science in Sports and Exercise, 41(1), 3-13. doi:10.1249/MSS.0b013e31818cb278

Hutnick, N. A., Williams, N. I., Kraemer, W. J., Orsega-Smith, E., Dixon, R. H., Bleznak, A. D., \& Mastro, A. M. (2005). Exercise and Lymphocyte activation following chemotherapy for breast cancer. Medicine and Science in Sports and Exercise, 37(11), 1827-1835. doi:10.1249/01. mss.0000175857.84936.1a

Ibrahim, E. M., \& Al-Homaidh, A. (2011). Physical activity and survival after breast cancer diagnosis: Meta-analysis of published studies. Medical Oncology, 28(3), 753-765. doi:10.1007/s12032-010-9536-X

Irwin, M. L., Cartmel, B., Gross, C. P., Ercolano, E., Li, F., Yao, X., ... Ligibel, J. (2014). Randomized exercise trial of aromatase inhibitor-induced arthralgia in breast cancer survivors. Journal of Clinical Oncology, 33 (10), 1104-1111. doi:10.1200/JCO.2014.57.1547

Jones, L. W., Courneya, K. S., Mackey, J. R., Muss, H. B., Pituskin, E. N., Scott, J. M., ... Haykowsky, M. (2012). Cardiopulmonary function and agerelated decline across the breast cancer survivorship continuum. Journal of Clinical Oncology, 30(20), 2530-2537. doi:10.1200/ JCO.2011.39.9014

Jones, L. W., Haykowsky, M. J., Swartz, J. J., Douglas, P. S., \& Mackey, J. R. (2007). Early breast cancer therapy and cardiovascular injury. Journal of the American College of Cardiology, 50(15), 1435-1441. doi:10.1016/j. jacc.2007.06.037

Knobf, T. M., \& Coviello, J. (2012). Lifestyle interventions for cardiovascular risk reduction in women with breast cancer. Current Cardiology Reviews, 7(4), 250-257. doi:10.2174/157340311799960627

Lahart, I. M., Metsios, G. S., Nevill, A. M., \& Carmichael, A. R. (2015). Physical activity, risk of death and recurrence in breast cancer survivors: $A$ systematic review and meta-analysis of epidemiological studies. Acta Oncologica, 54(5), 635-654. doi:10.3109/0284186X.2014.998275

Lahart, I. M., Metsios, G. S., Nevill, A. M., Kitas, G. D., \& Carmichael, A. R. (2016). Randomised controlled trial of a home-based physical activity intervention in breast cancer survivors. BMC Cancer, 16, 234. doi:10.1186/s12885-016-2258-5

Levine, B. D. (2008). VO2 max: What do we know, and what do we still need to know? The Journal of Physiology, 586(1), 25-34. doi:10.1113/ jphysiol.2007.147629

Matthews, C. E., Wilcox, S., Hanby, C. L., Der Ananian, C., Heiney, S. P., Gebretsadik, T., \& Shintani, A. (2007). Evaluation of a 12-week homebased walking intervention for breast cancer survivors. Support Care Cancer, 15(2), 203-211. doi:10.1007/s00520-006-0122-x

Mehnert, A., Veers, S., Howaldt, D., Braumann, K.-M., Koch, U., \& Schulz, K.H. (2011). Effects of a physical exercise rehabilitation group program on anxiety, depression, body image, and health-related quality of life among breast cancer patients. Onkologie, 34(5), 248-253. doi:10.1159/ 000327813

Miller, W. R., \& Rollnick, S. (2013). Motivational interviewing: Helping people change (3rd ed.). New York, NY: Guilford Press.

Patnaik, J. L., Byers, T., DiGuiseppi, C., Dabelea, D., \& Denberg, T. D. (2011). Cardiovascular disease competes with breast cancer as the leading cause of death for older females diagnosed with breast cancer: A retrospective cohort study. Breast Cancer Research and Treatment, 13 (3), R64. doi:10.1186/bcr2901

Peel, A. B., Thomas, S. M., Dittus, K., Jones, L. W., \& Lakoski, S. G. (2014). Cardiorespiratory fitness in breast cancer patients: A call for normative values. Journal of the American Heart Association, 3(1), e000432. doi:10.1161/JAHA.113.000432

Peel, J. B., Sui, X., Adams, S. A., Hebert, J. R., Hardin, J. W., \& Blair, S. N. (2009). A prospective study of cardiorespiratory fitness and breast cancer mortality. Medicine and Science in Sports and Exercise, 41(4), 742-748. doi:10.1249/MSS.0b013e31818edac7 
Pinto, B. M., Frierson, G. M., Rabin, C., Trunzo, J. J., \& Marcus, B. H. (2005) Home-based physical activity intervention for breast cancer patients. Journal of Clinical Oncology, 23(15), 3577-3587. doi:10.1200/ JCO.2005.03.080

Preacher, K. J., Rucker, D. D., \& Hayes, A. F. (2007). Addressing moderated mediation hypotheses: Theory, methods, and prescriptions. Multivariate Behavioral Research, 42(1), 185-227. doi:10.1080/00273170701341316

Robergs, R. A., \& Burnett, A. F. (2003). Processing data from indirect Calorimetry new concepts: Equipment testing and validation methods used to process data from indirect calorimetry and their application to VO2 max. Journal of Exercise Physiologyonline, 6(2), 44-57.

Rogers, L. Q., Hopkins-Price, P., Vicari, S., Pamenter, R., Courneya, K. S., Markwell, S., ... Lowy, M. (2009). A randomized trial to increase physical activity in breast cancer survivors. Medicine and Science in Sports and Exercise, 41(4), 935-946. doi:10.1249/MSS.0b013e31818e0e1b

Rosengren, D. B. (2009). Building motivational interviewing skills: A practitioner workbook. New York, NY: Guilford Press.

Sattelmair, J., Pertman, J., Ding, E. L., Kohl, H. W., Haskell, W., \& Lee, I. M. (2011). Dose response between physical activity and risk of coronary heart disease: A meta-analysis. Circulation, 124(7), 789-795. doi:10.1161/ CIRCULATIONAHA.110.010710
Shan, K., Lincoff, A. M., \& Young, J. B. (1996). Anthracycline-induced cardiotoxicity. Annals of Internal Medicine, 125(1), 47-58. doi:10.7326/ 0003-4819-125-1-199607010-00008

Shephard, R., \& Vuillemin, A. (2003). Limits to the measurement of habitual physical activity by questionnaires. British Journal of Sports Medicine, 37 (3), 197-206. doi:10.1136/bjsm.37.3.197

Speck, R. M., Courneya, K. S., Mâsse, L. C., Duval, S., \& Schmitz, K. H. (2010). An update of controlled physical activity trials in cancer survivors: A systematic review and meta-analysis. Journal of Cancer Survivorship: Research and Practice, 4(2), 87-100. doi:10.1007/s11764-009-0110-5

Spina, R. J. (1999). Cardiovascular adaptations to endurance exercise training in older men and women. Exercise and Sport Sciences Reviews, 27, 317-332. doi:10.1249/00003677-199900270-00012

Spina, R. J., Ogawa, T., Miller, T. R., Kohrt, W. M., \& Ehsani, A. A. (1993). Effect of exercise training on left ventricular performance in older women free of cardiopulmonary disease. The American Journal of Cardiology, 71(1), 99-104. doi:10.1016/0002-9149(93)90718-R

Thompson, B., Visich, P., Singleton, S., \& Saltarelli, W. (2003). Relationship of exercise intensity on individual and multiple CVD risk factors. Medicine and Science in Sports and Exercise, 35(Supplement 1), S343. doi:10.1097/00005768-200305001-01910 